Paper published in 2006, by:

Pasquet, P. , Monneuse, M.O., Simmen, B., Marez, A., \& Hladik, C.M., (2006) - Relationship between taste thresholds and hunger under debate. Appetite, 46: 63-66.

(Revised version of 9/09/2005, as submitted to Appetite)

\title{
The relationship between taste thresholds and hunger under debate
}

\author{
Patrick Pasquet ${ }^{1}$, Marie-Odile Monneuse ${ }^{1}$, Bruno Simmen ${ }^{1}$, André Marez ${ }^{2}$, \\ and Claude Marcel Hladik ${ }^{1}$
}

\begin{abstract}
${ }^{1}$ Centre National de la Recherche Scientifique (Paris, France, UMR 5145: Éco-Anthropologie et Ethnobiologie, Musée de l'Homme, 17 place du Trocadéro, 75116 Paris, France

2 Paris 12 University, Département Génie Biologique, Avenue du Général de gaulle, 94010, Créteil-
\end{abstract} France.

Correspondence to: Patrick Pasquet, UMR 5145, Éco-Anthropologie et Ethnobiologie, MNHN, Musée de l'Homme, 17 place du Trocadéro, 75116 Paris, France, e-mail : ppasquet@mnhn.fr

Running title: Gustatory thresholds and hunger

\begin{abstract}
We determined taste recognition thresholds for six compounds (sucrose, fructose, sodium chloride, quinine sulphate, PROP, and liquorice) in fasting students and, in the same subjects, after a meal. The testing procedure was the staircase-method in blind conditions. Although possible variation of taste sensitivity could be linked to internal state (i.e. hormonal status), our results did not show any significant variation of the taste recognition thresholds according to hunger or satiety. Our Bayesian analysis did not corroborate the hypothesis of increased sensitivity to nutrition-related tastants in the fasting state that was recently supported by published data obtained with the two-alternative forced-choice method.
\end{abstract}

Keywords: gustatory perception, hunger, satiety 


\section{Introduction}

In 1959, when Rose Mary Pangborn was testing the possible variation of taste recognition thresholds and sweetness preferences in relation to hunger and satiety, she drew the conclusion that the internal state has no pronounced effect on taste sensitivity, concluding a previous debate on the issue. Presently, the current claim is that most significant variations observed in relation to satiated or fasted conditions essentially concern the hedonic dimension of gustatory perception and not perception or recognition thresholds, considered as relatively stable individual sensory characteristics (Pangborn, 1959; Berridge, 1991).

However the evidence for relationship between taste perception and metabolic status (hunger, satiety, body weight and body composition) is far from being completely understood, because of the complex interaction of genetic, biological and psychological factors, in addition to methodological confounding factors (Nasser et al., 2001). Advances about this issue during the last decade have highlighted several points that might challenge classical views, especially concerning the peripheral modulation of taste responses by internal signals.

Variations of taste sensitivity (in terms of recognition or detection thresholds) according to pathology and hormonal status have been reported (Alberti-Fidanza et al., 1998; see also review in Bartoshuk et al., 2002). For instance variation of taste recognition thresholds for sodium chloride were observed in patients with chronic renal failure (Middleton and Allman-Farinelli, 1999). Furthermore, greater taste acuity for sucrose has been observed in massively obese subjects after gastric bypass (Burge et al., 1995). In the same vein, increased taste sensitivity with hunger has been observed in heavy overweight patients, during a fasting cure (Glockner et al, 1986).

Japanese studies on rodents have also shown that leptin, the hormone in adipose tissue which can decrease food intake, suppresses oral response to sweet stimuli when administered peripherally to lean mice, but not in obese, diabetic, leptin receptor-defective $\mathrm{db} / \mathrm{db}$ mice (Kawai et al., 2000; Shigemura et al., 2004). Taste cells in lean mice express the leptin receptor, but no report has been made of leptin receptors in human taste cells. However, such mechanisms implying variation of peripheral taste sensitivity related to leptin status are not excluded in humans, since taste detection thresholds measured by electrogustometry in children with obesity appeared lower than expected (Obrebowski et al. 2000). Similarly, some of us observed that taste recognition thresholds (especially for sucrose) are lower in massively obese adolescent than in non obese adolescents (Monneuse et al., 2003).

Such arguments led Zverev (2004) to reconsider the issue of a possible variation of taste threshold linked to caloric deprivation and/or satiety in lean normal subjects. Accordingly, he conducted a series of 
tests to determine taste recognition thresholds, with two-alternative forced-choice method, for sucrose, sodium chloride and quinine sulphate in a group of 16 lean male students. The Zverev study showed that short-term caloric deprivation is associated with a significant increase of the taste sensitivity to sucrose and sodium chloride solutions, but not to quinine. This suggests that variations in taste sensitivity involve only the perception of nutrients. Such unexpected results, if corroborated, could open a new direction of research on the link between taste perception and energy metabolism.

If short term internal signals can significantly modulate the taste thresholds, the utilisation of this parameter to compare individuals and populations would require a specific procedure taking into account such variations. Thus, considering the contradictory background of the research on this topic, and the few existing experimental results on humans since the study of Pangborn (1959), new measurements with a standard methodology (Simmen et al., 2004) were needed. This was the purpose of the tests presented in this paper, based on the staircase method allowing a relatively large number of tastants to be tested without tiring the assessors.

\section{Methods}

Two groups each containing 12 dietician students of both sexes (including 21 women and 3 men of mean age 26), non-smokers, and with a Body Mass Index lower than 25, were recruited at the University of Paris 12. After the subjects were informed of the purpose and the procedure (as described below), they signed a form of consent.

Both groups were tested twice, within two days interval: in the morning between 8:30 and 10 am, in the fasted state (after an overnight fast), and in the afternoon, about one hour after a standard lunch at the University cafeteria, completed, before the test, by ad libitum consumption of a standard dish of sweetened cream. One group was tested first in the fasted state, whereas the other one was first tested in the satiated state.

At the beginning of each testing session, subjective hunger magnitude was determined by self-report using the nine points scale labelled from 'not hungry at all' (1) to 'extremely hungry' (9). Determination of taste recognition thresholds were conducted by three of the authors (B.S., P.P., C.M.H.), trained to such practice, and each of the measurers was in charge of the same subjects in fasted and satiated states, without access to previous results when testing the second time.

Determination of taste thresholds was carried out in blind conditions (the order of presentation of the compounds was not known of the subjects), using a series of six pure chemicals in solution in a commercialized 
drinking water selected for its low mineral content. Twofold step series ( $0.3 \log$-step) included sucrose (2.0 to $1000 \mathrm{mM})$, fructose (2.0 to $1000 \mathrm{mM})$, quinine sulphate $(0.0004$ to $1.6 \mathrm{mM})$, and purified liquorice $(0.015$ to 1 g/1 of glycyrrhizin from Extrasynthese, Lyon, France), whereas the solutions of sodium chloride (1.77 to 1000 $\mathrm{mM}$ ) and 6-n-propylthiouracyl (PROP, 0.001 to $3.2 \mathrm{mM}$ ) were diluted with a 0.25 log-step.

The testing procedure was the staircase-method (modified from Cornsweet, 1962). Each subject was first informed on the taste categories he or she could be faced with, (such as water, salty, sweet, bitter, liquorice). The few subjects that did not know the taste of liquorice, (that has no odour, as all other tested substances) chewed a piece of the raw substance before the tests. Each assessor evaluated all six tastants. The six series of solutions were presented one after another, in a random order (except PROP, always kept as the last series, to avoid the persistence of a strong distasteful taste for some subjects). Within each series, the solutions were presented in order of ascending concentrations, and sipped by the assessor from a 2-ml plastic teaspoon. They were not swallowed, and the mouth was rinsed between two solutions with the same water as used to prepare the test solutions. The assessor had to correctly name the tastant in each series. Once the taste of two successive concentrations was recognised successfully, the subject was given the previous unrecognised concentration (first reversal). This up-and-down procedure was performed twice until the taste of two increasing stimuli was correctly named. The actual recognition threshold was calculated as the mean of the lowest concentrations recognised in each reversal.

The STATISTICA software, version 6.0 (Statsoft Inc., Ok, USA) was used for statistical analyses. The non-parametric Wilcoxon matched pairs test was used to estimate statistical significance of differences of the individual taste recognition thresholds, and subjective hunger ratings, in the fasted and the satiated states. The Mann-Whitney U test was used to compare the mean thresholds of two subgroups of subjects, those first tested in fasted condition vs. those first tested in satiated condition.

To extend traditional significance tests of differences in individual recognition thresholds in the fasted and in the satiated states, we used a standard Bayesian procedure, which provides probability statements about the true standardized population differences $(\delta / \sigma)$ according to the size of the sample, using LeBayesien software (Lecoutre and Poitevineau, 1996). For this purpose, we retained the criterion of Cohen (1969) who defined the cut-off limit for a "negligible" difference at $|\delta / \sigma|<0.2$.

\section{Results}

The mean recognition thresholds of 24 subjects, in fasted and satiated states for the 6 tested compounds, are presented in Table I. The mean values, as well as the inter-individual variation, are in the range of published data in various human population samples (Hladik et al., 1986; Hladik and Simmen, 1996; Pasquet, et al., 
2002). The proportion of subjects recognising each substance within \pm one step of concentration in both fasted and satiated states is $82 \%$ for fructose, $64 \%$ for sodium chloride, $77 \%$ for sucrose, $60 \%$ for PROP, $91 \%$ for quinine and $77 \%$ for liquorice. Table II provides the descriptive statistics of the within-subject differences in lowest correctly named concentration of the various tastants between fasted and satiated states.

\begin{tabular}{lcc}
\hline & Fasted & Satiated \\
\hline Sucrose (mM) & $40.1 \pm 7.2$ & $41.4 \pm 6.1$ \\
Fructose (mM) & $46.2 \pm 7.3$ & $53.8 \pm 12.0$ \\
Purified liquorice $(\mathrm{g} / \mathrm{l})$ & $0.12 \pm 0.02$ & $0.11 \pm 0.02$ \\
Sodium chloride $(\mathrm{mM})$ & $22.2 \pm 5.5$ & $19.3 \pm 4.3$ \\
PROP $(\mathrm{mM})$ & $0.33 \pm 0.14$ & $0.28 \pm 0.11$ \\
Quinine sulphate $(\mathrm{mM})$ & $0.0089 \pm 0.003$ & $0.0068 \pm 0.002$ \\
\hline
\end{tabular}

Table I. Mean ( \pm SE) recognition thresholds of 24 subjects tested during fasted and satiated states

The Wilcoxon matched pairs test applied on individual taste thresholds in satiated and fasted states does not show any statistically significant variation for both sugars (sucrose and fructose), purified liquorice, sodium chloride, PROP or quinine sulphate $(\mathrm{p}>0.20)$. Similarly, considering the order of testing of the two groups, no significant difference was found with the Mann-Whitney U test, for each substance and for each state, thus implying that no significant learning resulted from the first practice of the test.

\begin{tabular}{|c|c|c|c|c|c|c|c|c|}
\hline & & & $\begin{array}{r}P \text { u } \\
\text { liquorice }(g / l)\end{array}$ & $\begin{aligned} \text { i f i e d } & S \text { o } \\
& \text { chloride }(\mathrm{mM})\end{aligned}$ & d i u & & $\begin{array}{r}\mathrm{Qu} \\
\text { sulphate }(\mathrm{mM})\end{array}$ & i $\mathrm{n} \mathrm{i} \mathrm{n} \mathrm{e}$ \\
\hline & Mean & - & & 0.08 & -1.65 & & & 0.006 \\
\hline & Median $^{-2.52}$ & 6.14 & & 0.06 & 0.00 & 0.13 & & 0.002 \\
\hline & Lower 0.00 & 0.00 & - & -0.08 & -7.70 & & - & -0.001 \\
\hline quartile & Upper 30.32 & 15.60 & & 0.25 & 5.55 & 0.002 & & 0.007 \\
\hline quartile & 15.16 & 23.45 & & & & 0.02 & & \\
\hline
\end{tabular}

Table II. Descriptive statistics of the within-subject differences in lowest correctly named concentration of the various tastants between fasted and satiated states.

The mean levels of hunger assessed by subjective rating on the nine point scale differs significantly between the fasted and the satiated states (respectively $5.4 \pm 2.2$ and $1.8 \pm 0.9$; Wilcoxon matched pairs test: $\mathrm{p}<0.0001)$.

We applied a Bayesian procedure to the log of the concentration values instead of crude concentration values, considering their more normal-like distribution. From the standard Bayesian probabilities for a negligible value $(\mathrm{p}[|\delta / \sigma|<0.2])$, and considering the actual sample size of 24 subjects, it is not possible to reach a clear conclusion, since probabilities are not high enough. They are respectively: $0.70 ; 0.55 ; 0.67 ; 0.39 ; 0.65 ; 0.53$ for fructose, sucrose, sodium chloride, PROP, quinine, and liquorice. 
Although we cannot conclude on the negligibility of the difference, for any tastant, between fasted and satiated state, these results do not confirm the hypothesis of Zverev of an increased sensitivity for sugars and sodium chloride in the fasted state, since, at least for fructose and sodium chloride, we found a relatively high probability for a difference in the opposite direction (decreased sensitivity): for fructose, $p[\delta / \sigma>0]=0.65$, and for sodium chloride, $\mathrm{p}[\delta / \sigma>0]=0.61$.

\section{Discussion}

As in most previous studies, we cannot ascertain the negligibility of the effect of hunger and satiety on taste thresholds. Despite a tendency towards greater sensitivity with food deprivation, Pangborn (1959) after measuring taste identification thresholds for sucrose, sodium chloride, citric acid and caffeine of eight subjects in fasted and in satiated conditions, concluded that no significant variation occurs. The significant difference of the recognition thresholds for sucrose and sodium chloride observed by Zverev (2004) on 16 subjects (two groups of 8) in fasted and in satiated conditions was not found in our study, using a larger set of subjets and compounds. Here, we considered that the variety of the compounds we used (including sucrose, sodium chloride and quinine sulphate, as in Zverev study) was a prerequisite to effectively operate in blind conditions. In our study, including a majority of women, a possible masking effect due to variation of taste threshold during menstrual cycle (Alberti-Fidanza et al., 1998) was unlikely given the proximity of the two sessions (respectively two and three days for each group).

Variation of taste recognition thresholds may occur, for instance for sodium chloride in patients with chronic renal failure (Middleton and Allman-Farinelli, 1999). This, however, is obviously not reflecting any short term effect of caloric intake. Variation of taste threshold for sugars along with the internal state could also be hypothesized, based on results of a study carried out in a primate species, Microcebus murinus, in which both body weight and ingestive responses to sucrose solutions vary seasonally to a great extent. However, despite such behavioural variation associated with taste perception, the signal recorded on the peripheral taste nerve of this primate species does not vary concomitantly (Hellekant et al., 1993). Whether this primate prefers sucrose solutions over pure water only at high concentration, or whether it prefers more diluted sucrose solutions over water, the signal recorded on the taste nerve remains the same (Simmen and Hladik, 1988; Hellekant et al., 1993).

A similar conclusion can be drawn from a study on a macaque by Yaxley et al. (1985), showing that satiety does not affect gustatory activity in the nucleus of the solitary tract, the first relay of the peripheral taste signal. 
Although the accuracy of taste recognition thresholds depends on the number of dilutions provided as well as on the step between concentrations - which in turn are adjusted according to the ability of volunteers to concentrate their attention on the difficult task of taste recognition —, such measurements are reliable enough to assess individual taste sensitivity to compare individuals and populations. In this respect, significant differences of taste recognition thresholds have been found in relation to food preferences, which would not be expected if thresholds were highly variable biological traits (Pasquet et al., 2002).

Each compound could be considered as a probe to investigate part of the tasting system, but does not correspond to a "basic taste" since the peripheral taste signal is complex and specific to each compound. Partial similarities of perceived tastes, such as those shown by Schiffman and Erickson (1971) for various salts, correspond to partial similarities between peripheral signals as indicated by the work on non-human primates of Scott and Plata-Salamán (2004). In humans the correlation analysis performed among taste thresholds for various compounds is a way to highlight relationships among corresponding taste signals, which most often result from evolutionary pressures and adaptation (Hladik et al., 2003).

Whereas variations of taste sensitivity could be linked to internal state, our results failed to demonstrate any statistical difference in taste recognition thresholds between the fasted and the satiated states, and do not support the hypothesis of increased sensitivity to nutrition-related tastants in the fasted state.

\section{References}

Alberti-Fidanza, A., Fruttini, D. \& Servili, M. (1998). Gustatory and food habit changes during the menstrual cycle. International Journal of Vitamin and Nutrition Research, 68, 149-153.

Bartoshuk, L.M., Duffy, V.B., Fast, K., Green, B.G. \& Snyder, D.J. (2002). Hormones, age, genes and pathology: How do we assess variation in sensation and preference? In: Anderson, H., Blundell, J. \& Chiva, M. (Eds) Food Selection: from Genes to Culture, pp. 173-188., Paris, France: Danone Institute.

Berridge, K.C. (1991). Modulation of taste affect by hunger, caloric satiety, and sensory-specific satiety in the rat. Appetite, 16: 103-120.

Burge, J.C, Schaumburg, J.Z., Choban, P.S., DiSilvestro, R.A. \& Flancbaum, L. (1995). Changes in patients' taste acuity after Roux-en-Y gastric bypass for clinically severe obesity. Journal of American Dietetic Association, 95, 666-670.

Cohen, J. (1969). Statistical Power Analysis for the Behavioral Sciences. Academic Press, New York.

Cornsweet, T.N. (1962). The staircase-method in psychophysics. American Journal of Psychology, 75, 485-491. 
Glockner, L., Fikentsher, R. \& Ulrich, F.E., (1986). Taste perception in fasting overweight patients. $Z$. Gesamte Inn Med, 41, 244-246.

Hellekant, G., Hladik, C.M., Dennys, V., Simmen, B., Roberts, T.W. \& Glaser, D. (1993). On the relationship between sweet taste and seasonal body weight changes in a primate (Microcebus murinus), Chemical Senses, 18, 27-33.

Hladik, C.M., Robbe, B. \& Pagezy, H. (1986). Sensibilité gustative différentielle des populations Pygmées et non Pygmées de forêt dense, de Soudaniens et d'Eskimos, en rapport avec l'environnement biochimique. C. R. Acad. Sc. Paris, (série III) 303, 453-458.

Hladik, C.M. \& Simmen, B. (1996). Taste perception and feeding behavior in non-human primates and human populations. Evolutionary Anthropology, 5, 58-71.

Hladik, C.M., Simmen, B. \& Pasquet, P. (2003). Primatological and anthropological aspects of taste perception and the evolutionary interpretation of "basic tastes". Anthropologie, 41, 9-16.

Kawai K, Sugimoto K, Nakashima K, Miura H, Ninomiya Y. (2000) - Leptin as a modulator of sweet taste sensitivities in mice. Proceedings of the National Academy od Sciences (USA) 2000; 97: 11044-11049.

Lecoutre, B. \& Poitevineau, J. (1996). LeBayésien, Windows software. Supplied in Lecoutre B., 1996, Traitement statistique des données expérimentales : des pratiques traditionnelles aux pratiques bayésiennes. C.I.S.I.A., Saint Mandé, France.

Monneuse, M.O., Frelut, M.L., Rigal, N., Marez, A., Simmen, B., \& Pasquet, P. (2003). Relations entre les perceptions et les préférences alimentaires d'enfants obèses pendant une cure d'amaigrissement. XII èmes Rencontres Scientifiques de Nutrition: Goûts et comportements alimentaires de l'enfant. Décembre 2003, Paris

Middleton, R.A. \& Allman-Farinelli, M.A. (1999). Taste sensitivity is altered in patients with renal chronic failure receiving continuous ambulatory peritoneal dialysis. Human Nutrition and Metabolism, 0022$3166 / 99,122-125$.

Nasser, J. (2001). Taste, food intake and obesity. Obesity Reviews, 2, 213-218.

Obrebowski, A., Obrebowska- Karsznia, Z. \& Gawlinski, M. (2000). Smell and taste in children with simple obesity. International journal of Pediatric Otorhinolaringology, 55: 191-196.

Pangborn, R.M. (1959). Influence of hunger on sweetness preferences and taste thresholds. American Journal of Clinical Nutrition, 7, 280-286.

Pasquet, P., Oberti, B., El Ati, J. \& Hladik, C.M. (2002). Relationships between threshold-based PROP sensitivity and food preferences of Tunisians. Appetite, 39, 167-173.

Schiffman, S.S. \& Erickson, R.P. (1971). A psychological model for gustatory quality. Physiology and Behavior, 7, 617-633.

Scott, T.R. \& Plata-Salamán, C.R. (2004). Les goûts des sels chez le macaque, Macaca fascicularis, et leurs relations avec les perceptions chez l'homme. Primatologie, 6, 33-45.

Shigemura, N., Ohta, R., Kusakabe, Y., Miura, H., Hino, A., Koyano, K., Nakashima, K,\& Ninomiya, 
Y. (2004) - Leptin modulates behavioral responses to sweet substances by influencing peripheral taste structures. Endocrinology, $145: 839-847$.

Simmen, B. \& Hladik, C.M. (1988). Seasonal Variation of Taste Threshold for Sucrose in a Prosimian Species, Microcebus murinus. Folia Primatologica, 51, 152-157.

Simmen, B., Pasquet, P., \& Hladik, C.M. (2004). Methods for assessing taste abilities and hedonic responses in human and non-human primates. In : Macbeth, H. \& MacClancy, J. (eds) Researching Food Habits: Methods and Problems, pp. 87-99. Berghahn Books, Oxford.

Yaxley, S., Rolls, E.T., Sienkiewicz, Z, J \& Scott, T.R (1985). Satiety does not affect gustatory activity in the nucleus of the solitary tract of the alert monkey. Brain Research, 347, 85-93.

Zverev, Y. (2004). Effect of caloric deprivation and satiety on sensitivity of the gustatory system. $B M C$ Neuroscience, 5, 5 (http://www.biomedcentral.com/1471-2202/5/5). 